\title{
Canada's Newest Electrical Engineering Curriculum: Driving Factors and Critical Requirements
}

\author{
A. Grami and M.A. Rosen \\ University of Ontario Institute of Technology, Oshawa, Canada \\ ali.grami@uoit.ca_marc.rosen@uoit.ca
}

\begin{abstract}
UOIT's Electrical Engineering program was launched in September 2005. The driving factors and critical requirements for this program were unique, and led to the development of a curriculum which is innovative in many respects, yet maintains the best features of traditional EE programs. The development effort focused on the quality of the curriculum, in terms of content, pedagogy and delivery, as quality is important to students, prospective employers, graduate schools, accreditation bodies and the engineering community. Since the notion of quality is always multi-dimensional, we provide here the rationale for the EE program from many perspectives: generalized vs. specialized, problem solving vs. engineering design, technical vs. complementary studies, circuits vs. signals, analog vs. digital, lab experimentation vs. computer simulation, and knowledge-sake vs. market-oriented.
\end{abstract}

\section{Introduction}

Bill 109, an Act to establish the University of Ontario Institute of Technology (UOIT), was passed by the Ontario Legislature on June 27, 2002, creating Canada's newest university. The underlying reasons why a university was created in Durham region are its rapid population growth and relatively low proportion of university participation. UOIT offers select marketoriented and innovative programs.

UOIT is Ontario's only laptop university, and among the few universities in the world where every seat in classrooms and laboratories is connected to the Internet and the faculty are required to appropriately integrate the use of technology into the teaching learning enterprise. A vision for the use of laptops was developed and embedded in UOIT's strategic vision, for their use was seen as providing an opportunity for teaching innovation and excellence. Every student at UOIT has a laptop PC and every engineering faculty member has a tablet PC, all with specialized software to meet the needs of specific academic programs. Use of Information and Communication Technology (ICT) can help engineering students learn more efficiently and effectively, and allow instructor and student time to be effectively utilized. In addition, use of ICT can help students become fully comfortable and competent with the enhanced computational capabilities and modeling, simulation and other software tools available, thus making them more attractive to potential employers, during their studies and upon graduation. Research supports the use of technology as a catalyst for improving the learning environment, even though having laptops in Internet-enabled classrooms for use by students during lectures can create challenges for instructors regarding how to channel student attention exclusively on what is being discussed during the class [1].

UOIT offers bachelor programs in Manufacturing Engineering, Mechanical Engineering, Automotive Engineering, Nuclear Engineering, Energy Systems Engineering, Electrical Engineering, and Software Engineering. The Faculty of Engineering and Applied Science at UOIT is growing quickly, and is expected to reach a steady state of about 1200-1600 undergraduate students by 2010 .

\section{UOIT's Electrical Engineering Program}

UOIT's Electrical Engineering (EE) program was launched in September 2005. The EE program map, as shown in Table-1, highlights a broad program, constituting diverse areas of specialization, such as circuits and electronics, electromagnetics and power, 
communications and control, and computer hardware and software. About half of the courses in the undergraduate curriculum are electrical engineering based, and the other half are mathematics, science, professional, and liberal studies courses. The first-year courses are the same as those for most of UOIT's other engineering programs, except for the course Information Technology for Engineers. This course is included in the first semester to reflect a spiral curriculum approach [2], where certain important topics are introduced at a simple level and subsequently revisited in more depth over half a dozen courses. Figure 1 highlights the goals of the program. Techniques to improve EE education pedagogy are utilized in all courses, and include the dynamics of learning which highlights self-learning through interactive laptop computers, and the dynamics of teaching which emphasizes the role of the teacher as the stimulator of student learning [3].

The content of the undergraduate EE curriculum is challenging and sizable. The curriculum is kept broad so as to enhance the breadth of technical contributions that graduates can deliver in industry. This is in contrast to targeted undergraduate programs that highlight depth of knowledge in select areas. We believe that a generalized and comprehensive undergraduate curriculum can provide entry-level graduates with a profound understanding of broad and universally important principles, as well as abilities to learn and adapt to technological advances.

The quality of the curriculum can be measured by its content, pedagogy and delivery. Course types, contents, and sequences form a crucial factor in shaping graduates, for they must motivate students, and provide them with the knowledge and skills needed to enter professional practice or undertake graduate studies. The pedagogy employed is important as it must ensure that students have a solid understanding of engineering principles and the ability to think critically and solve problems. Delivery is heavily influenced by learning technologies, where they are meaningfully integrated into education and diffused throughout the program, not for their own sake or novelty, but with the expectation of increased, enhanced and more motivated learning. Technology can enhance learning when the pedagogy is sound, and when there is good match between educational technology, learning styles, outcomes and participation [1]. Learning-teaching technologies may include university-wide learning management systems, power-point-presentation-based lectures combined with learning objects, in-class/lab high-speed Internet access, math and simulation packages (such as Matlab, PSpice and Labview), and interactive video and video vignettes.

\section{Program Stakeholders}

Figure 2 presents the curriculum drivers for UOIT's Electrical Engineering program. The main stakeholders in the Electrical Engineering curriculum are students, watchdogs (regulatory bodies and professional associations) and employers, each wanting to shape the curriculum to meet specific requirements.

Students, particularly those in first year, have a wide array of interests and goals as well as diverse learning styles and ICT ability, which the curriculum needs to accommodate. This is done by making courses i) diverse in tone and applications so as to accommodate on-going changes, and ii) relevant to expectations in terms of technical content, use of learning technologies, and engineering design. The objective is to attract and retain students who can have productive careers in engineer and related fields. This objective is achieved through increasing the correlation between engineering ingenuity and student grades.

A small portion of the graduating class is expected to attend graduate schools, leaving the majority likely to seek engineering opportunities in industry and government (at all levels). Engineering employments for electrical engineers are diverse, yet most have certain common requirements. The skill sets industry generally seek in hires include solid technical knowledge and diverse interests, a willingness and ability to adapt, learn and work hard, strong communications and teamwork skills, and broad understanding of technology, society and business. The courses in science, basic engineering and electrical engineering, as well as those in complementary studies, are mainly intended to provide a comprehensive view of electrical engineering so as to prepare students for industry. This preparation is important even for those who pursue graduate studies, as they also need to understand industry needs. In order to prepare students for industry, faculty members are often sought who have industrial work experience, along with demonstrated excellence (or great potential) in teaching and research.

The quality of a program is critical to its success. In order to ensure international standards in new degree programs in Ontario, the Postsecondary Education Quality Assessment Board (PEQAB) is mandated to assess new applications and thereafter to make recommendations to the Minister of Training, Colleges and Universities [4]. University of Ontario Institute of Technology has agreed since its inception to have all programs it offers assessed by PEQAB and recommended before being offered. As part of UOIT's commitment to quality, a detailed and comprehensive proposal for the EE program was submitted to 
PEQAB, highlighting the overall program design and outcomes, detailed course descriptions, and explanations of student preparation for employment and graduate studies. The program is expected to meet a substantial set of criteria and to lead to outcomes that have historically been and continue to be critical. Highly-qualified assessors review the proposal and undertake a site visit to learn about roll-out plans, view labs and meet faculty members. The assessors considered a variety of expected student outcomes: i) depth and breadth of knowledge in as well as outside the field, so as to have an understanding of the principal assumptions, methodologies, and applications in the field and its interactions with other disciplines, ii) conceptual and methodological awareness, in order to be able to devise and sustain arguments and solve practice-related problems, iii) a level of analytical skill that allows for reviewing, presenting, and critically evaluating qualitative and quantitative data, and applying underlying principles and concepts, iv) a level of application knowledge that allows for critical analysis of abstract concepts and data to achieve a solution or a range of solutions, v) professional traits, including initiative, responsibility and accountability as well as self-learning in a changing environment, vi) a level of communication skills sufficient to ensure information, arguments, and analyses can be accurately and reliably conveyed and exchanged among team members, and vii) an awareness of the limits of knowledge, and an ability to assess analyses and interpretations appropriately.

In 1965, the Canadian Council of Professional Engineers established the Canadian Engineering Accreditation Board (CEAB) to accredit Canadian Engineering programs that meet or exceed educational standards acceptable for professional engineering registration in Canada [5]. The CEAB reassesses accredited programs at intervals normally not exceeding six years and often more frequently. The curriculum content is assessed to ensure adequate coverage of mathematics, basic sciences, engineering sciences, engineering design and non-technical complementary studies. UOIT's Electrical Engineering program is designed to meet the curriculum and other requirements for accreditation by the CEAB (including appropriate space, lab facilities and equipment, experiments, software packages, and faculty credentials).

\section{Program Perspectives}

The quality of the curriculum, in terms of content, pedagogy and delivery, is the fundamental measure by which students, prospective employers, graduate schools, and the engineering community evaluate
UOIT's EE program. Since the notion of quality is always multi-dimensional, we provide here the rationale for the EE program from a variety of perspectives.

Circuits vs. Signals [6]: For decades, circuit analysis was a reasonable focal area in EE curricula, for many of the incoming students were hands-on types. But incoming students now have experience with complex electronic systems, where individual components are inaccessible. The shift is now towards signal processing - processing of audio and video signals and writing codes for DSP microprocessors. To this effect, the curriculum does not include traditional courses, such as Circuit Analysis, Circuit Theory, and Network Synthesis; instead the focus is on courses such as Digital Systems, Signals and Systems, and DSP Theory and Design.

Analog vs. Digital [7]: Digital has numerous benefits, including ease of multimedia content manipulation, bandwidth reduction, low-cost advanced processing and storage technology, and performance improvement. To this effect, in the curriculum, many digital principles are taught before, or in place of or more comprehensively than, analog concepts. Examples include the Communication Systems course, where AM and FM techniques are discussed briefly to allow full coverage of PCM and digital modulation techniques, the Signals and Systems course, where discrete convolution is taught first to better understand the complex concept of continuous convolution, and the Probability and Random Signals course, where probability distribution and density functions are discussed in the context of both discrete and continuous domains.

Problem Solving vs. Engineering Design: Problem solving is at the core of engineering, and is in fact what attracts many students to the engineering discipline. Problem solving in UOIT's EE curriculum is first taught in Math and Science courses, then extensively discussed in introductory courses, such as Programming and Electronics, and continually highlighted throughout the program. Engineering design (e.g., the integration of mathematics and engineering sciences, and possibly liberal studies, in developing systems to meet specific needs) is of paramount importance. This is not only reflected in a significant design experience, i.e., Electrical Engineering Systems Design and Design Thesis in the fourth year, but in many courses in the curriculum. There is a heavy emphasis on engineering design in third and fourth year courses, such as Signals and Systems, Microprocessor Systems Design, Electronics Circuit Design, Electric Machines, Microwave and RF Circuits, and Modern Control Systems, where engineering design is not only extensively discussed, 
but students are expected to make specific designs, usually through course projects.

Generalized vs. Specialized [3]: The UOIT EE program is quite comprehensive, in that all major areas of EE are covered. The reason for this approach is that we believe a generalized undergraduate curriculum provides graduates with a profound understanding of broad and universally important principles, as well as abilities to learn about emerging technological advances. We further believe specialized knowledge and technical expertise can be gained in industry through on-the-job training or at the university through graduate programs. Also, instead of making the program specialized through a large set of technical elective and/or core courses, we propose specialized undergraduate programs be offered to meet specific engineering needs in the electrical engineering arena. We envisage five such paths. In 2005, we launched Software Engineering, and in the next couple of years, we plan to offer Computer Engineering. The plan also includes, depending on market demand and the availability of university resources, programs in Communications Engineering [8], Biomedical Engineering, and Power Engineering [9].

Lab Experimentation vs. Computer Simulation [1]: This program was designed to require a level of abstract thinking, conceptual sophistication, theoretical knowledge, and intellectual autonomy. Simultaneously, the curriculum was fundamentally oriented towards practice and experimentation, e.g., testing theory, an inherent component of an Electrical Engineering program. To achieve that, we foster both lab experimentation and computer simulation, for one can enhance the understanding of the other. State-ofthe-art lab equipment for electronics, communications, machines, control and digital systems enable students to do experiments to validate the theory and design, and to enhance their acquired hands-on knowledge through computer simulation. In fact, computer simulation can complement lab experimentation in virtually all courses, especially when the experiment duration needs to be long or the laboratory process and accompanying hardware are complex and costly.

Technical vs. Complementary Studies: It is imperative that the curriculum includes a reasonable coverage of complementary studies, to ensure engineers develop skills in interacting with people and understand the social ramifications of technological development. Agencies that assess engineering programs for quality, such as the $\mathrm{CEAB}$, require such coverage. Complementary studies help instill in engineers attributes such as flexibility, diligence, and a desire to learn quickly, thereby increasing how they are suited to serve the needs of industry. Six diverse courses on liberal and complementary studies play a critical role in furnishing students with soft skills, critical thinking, and teamwork abilities, and an understanding of the societal impact and benefits of engineering. In addition, students take two professional courses that provide them with the skills necessary for responsible decision making in complex and unpredictable situations, which often prevail in industry.

Knowledge-Sake vs. Market-Oriented: The EE program was designed to have a balance between the traditional knowledge-sake approach and the emerging market-oriented mandate, for we believe they have a symbiotic relationship and together improve teaching and learning. We avoid having the program exclusively focus on market needs, even though it may help graduates find employment quickly and employers obtain highly qualified and trained electrical engineers, because such an approach usually does not instill initiative and creativity. These attributes are essential for giving students a desire and ability to advance knowledge and better life-by advancing ideas and concepts beyond what market may want or need, to what the marketplace can potentially and eventually offer. The curriculum strives to allow students to seek knowledge, to push the technological envelope and to meet as well as drive market requirements.

\section{Conclusions}

The Electrical Engineering program at the UOIT offers a sound and comprehensive educational program that meets well all pertinent requirements of key stakeholders. From content, pedagogy and delivery standpoints, the program is also adaptive, allowing it to evolve to better serve the needs of students, prospective employers, regulatory bodies and, above all, the good of the engineering community and society. Such adaptability is critical since the discipline of engineering is always evolving due to constant technical and technological advances and, in case of Electrical Engineering, the pace is quite rapid.

\section{References}

[1] A. Grami, G.S. Rao, and M.A. Rosen, "Use of laptops in internet-enabled learning spaces: enhancing electrical engineering education," Proceedings of the CDEN International Conference on Design Education, Innovation, and Practice, Kananaskis, Alberta, July 2005.

[2] J.A. Orr, W.H. Eggimann, D. Nicoletti, and D. Cyganski, "An electrical engineering curriculum beginning in the first year," Proceedings of Frontiers in Education Conference, pp. 342-346, November 1994. 
[3] F.C. Berry, P.S. DiPiazza, and S.L. Sauer, "The future of electrical and computer engineering educations," IEEE Transactions on Education, Vol. 46, No. 4, pp. 467-476, November 2003.

[4] Postsecondary Education Quality Assessment Board (PEQAB), "Handbook for Public Organizations," Government of Ontario, February 2006.

[5] Canadian Council of Professional Engineers, Canadian Engineering Accreditation Board, Accreditation Criteria and Procedures, 2005.

[6] D.C. Munson Jr., "Elements of a new electrical engineering curriculum at Illinois: a shift from circuits to signal processing," Proceedings of International
Symposium on Circuits and Systems, pp. 1-4, May 1995.

[7] G.H. Harris, "It's about time - digital before analog," Proceedings of International Symposium on Circuits and Systems, pp. 5-8, May 1995.

[8] D.C. Coll, "Communications engineering: a new discipline for the $21^{\text {st }}$ century," IEEE Transactions on Education, Vol. 37, No. 2, pp. 151-157, May 1994.

[9] G. Joos, R.J. Marceau, G. Scott, and D. Peloquin, "An innovative industry-university partnership to enhance university training and industry recruiting in power engineering," IEEE Transactions on Power Systems, Vol. 19, No. 1, pp. 24-30, February 2004.

Table 1. Electrical Engineering Program Map

\begin{tabular}{|c|c|c|c|c|c|}
\hline Physics-I & Calculus-I & $\begin{array}{c}\text { Info Tech } \\
\text { for Engineers }\end{array}$ & $\begin{array}{c}\text { Linear Algebra } \\
\text { for Engineers }\end{array}$ & $\begin{array}{c}\text { Technical } \\
\text { Communications }\end{array}$ & \\
\hline Physics-II & Calculus-II & $\begin{array}{c}\text { Chemistry } \\
\text { For Engineers }\end{array}$ & $\begin{array}{c}\text { Collaborative } \\
\text { Leadership }\end{array}$ & $\begin{array}{c}\text { Introduction to } \\
\text { Programming }\end{array}$ & $\begin{array}{c}\text { Impact of Sci \& } \\
\text { Tech on Society }\end{array}$ \\
\hline EE & $\begin{array}{c}\text { Discrete } \\
\text { Futhematics }\end{array}$ & $\begin{array}{c}\text { Software } \\
\text { Design-I }\end{array}$ & $\begin{array}{c}\text { Differential Eqs. } \\
\text { for Engineers }\end{array}$ & $\begin{array}{c}\text { Liberal Studies } \\
\text { Electives }\end{array}$ & \\
\hline $\begin{array}{c}\text { Introductory } \\
\text { Electronics }\end{array}$ & $\begin{array}{c}\text { Complex } \\
\text { Analysis for EE }\end{array}$ & $\begin{array}{c}\text { Digital } \\
\text { Systems }\end{array}$ & $\begin{array}{c}\text { Fundamentals of } \\
\text { Electromagnetics }\end{array}$ & $\begin{array}{c}\text { Liberal Studies } \\
\text { Electives }\end{array}$ & \\
\hline $\begin{array}{c}\text { Thermodynamics } \\
\& \text { Heat Transfer }\end{array}$ & $\begin{array}{c}\text { Signals \& } \\
\text { Systems }\end{array}$ & $\begin{array}{c}\text { Computer } \\
\text { Architecture }\end{array}$ & $\begin{array}{c}\text { Applications of } \\
\text { Electromagnetics }\end{array}$ & $\begin{array}{c}\text { Liberal Studies } \\
\text { (Adv) }\end{array}$ & \\
\hline $\begin{array}{c}\text { Electronic } \\
\text { Circuit Design }\end{array}$ & $\begin{array}{c}\text { Communication } \\
\text { Systems }\end{array}$ & $\begin{array}{c}\text { Microprocessor } \\
\text { Systems Design }\end{array}$ & $\begin{array}{c}\text { Electric } \\
\text { Machines }\end{array}$ & $\begin{array}{c}\text { Probability \& } \\
\text { Random Signals }\end{array}$ & Economics for \\
\hline $\begin{array}{c}\text { Microwavessionals } \& \\
\text { RF Circuits }\end{array}$ & $\begin{array}{c}\text { DSP Theory } \\
\& \text { Design }\end{array}$ & $\begin{array}{c}\text { Computer } \\
\text { Networks }\end{array}$ & $\begin{array}{c}\text { Engineering } \\
\text { Elective* }\end{array}$ & $\begin{array}{c}\text { Electrical Eng. } \\
\text { Systems Design }\end{array}$ & \\
\hline $\begin{array}{c}\text { Modern } \\
\text { Control Systems }\end{array}$ & Wireless & $\begin{array}{c}\text { Power } \\
\text { Communications }\end{array}$ & $\begin{array}{c}\text { Ethics \& Law } \\
\text { for Professionals }\end{array}$ & $\begin{array}{c}\text { Design } \\
\text { Thesis }\end{array}$ & \\
\hline
\end{tabular}

* Engineering Electives:

- Optical Communications

- Computer Design Graphics

- Multimedia Systems 


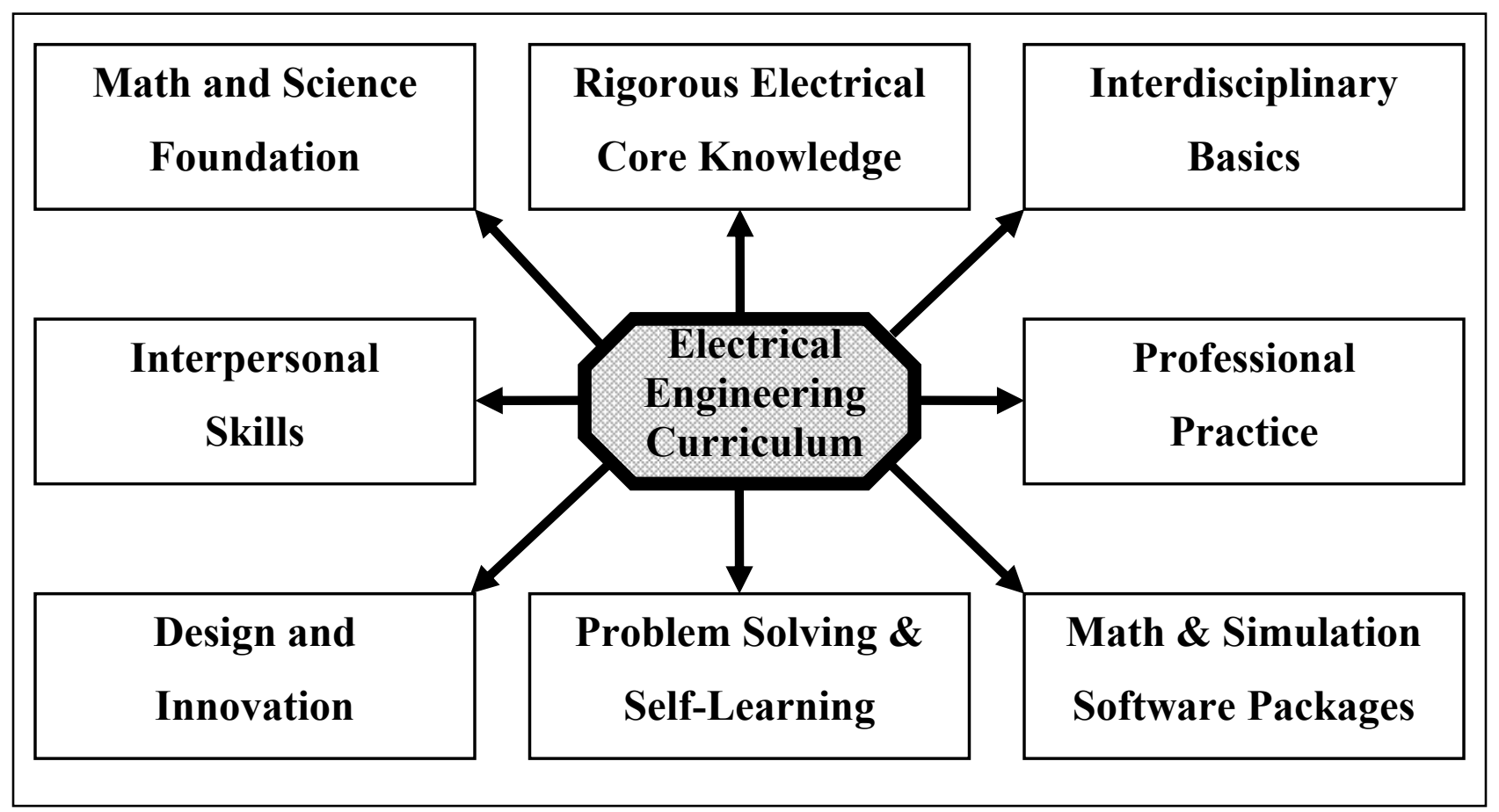

Figure 1. Electrical Engineering Curriculum Goals

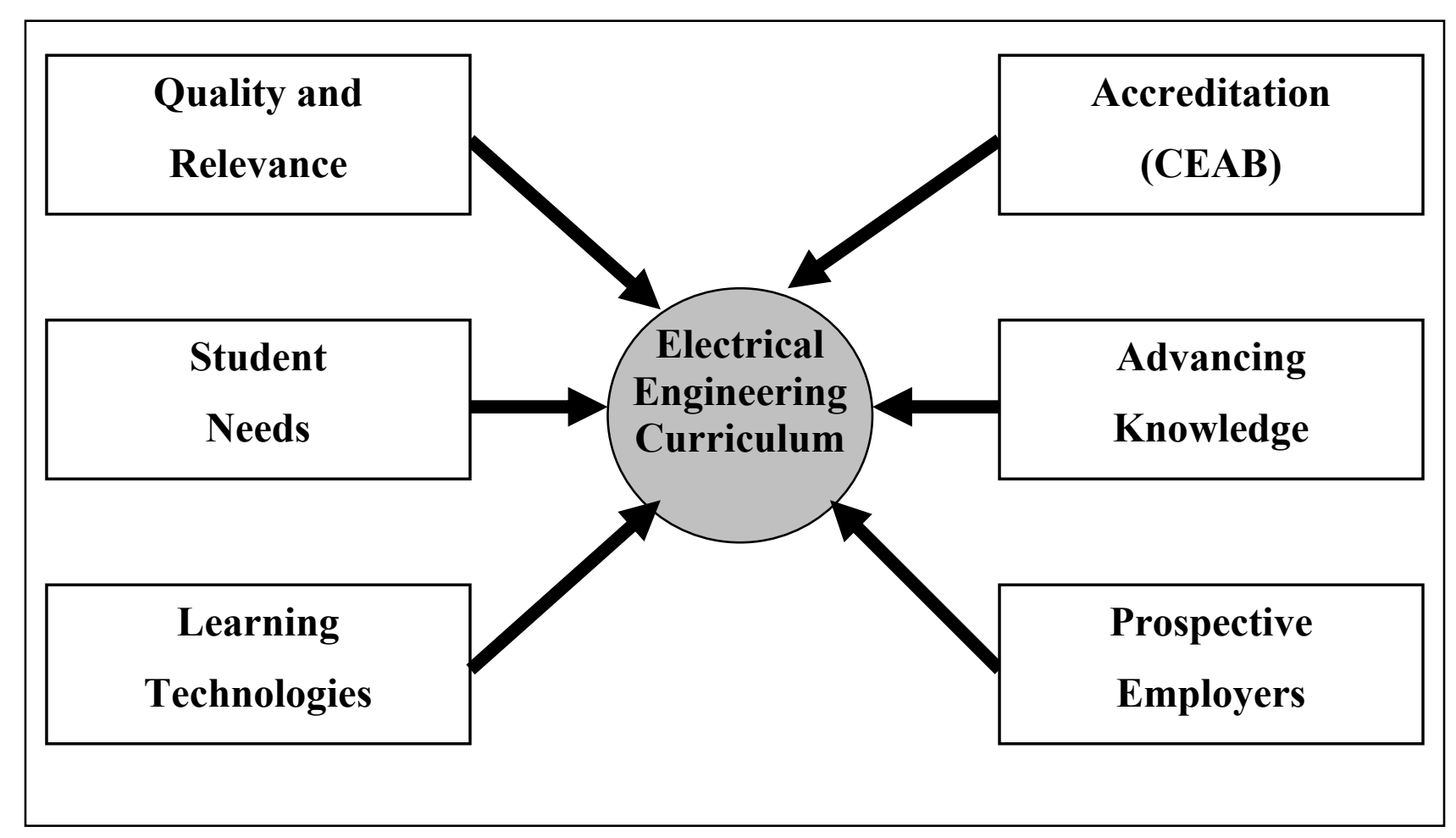

Figure 2. Electrical Engineering Curriculum Drivers 